\title{
Lymphophagocytosis in Pleural and Pericardial Fluids: An Ominous Finding
}

\author{
Aastha Sharma ${ }^{1}$ Ruchita Tyagi ${ }^{1}$ Pavneet Kaur Selhi ${ }^{1}$ \\ Harpreet Kaur $^{1}$ Neena Sood ${ }^{1}$ \\ 1Department of Pathology, Dayanand Medical College and Hospital, \\ Ludhiana, Punjab, India \\ 2Department of Oncology, Dayanand Medical College and Hospital, \\ Ludhiana, Punjab, India \\ ${ }^{3}$ Department of Cardiology, Dayanand Medical College and \\ Hospital, Ludhiana, Punjab, India
}

J Lab Physicians 2021;13:95-96.

Lymphophagocytosis can be seen either in primary hemophagocytic lymphohistiocytosis (HLH) syndrome or secondary to infections (viral, bacterial, fungal, or protozoal), immunosuppression, drug reaction, or, rarely, malignancy..$^{1-3}$ We present the case of a 17 -year-old male in whom lymphophagocytosis accompanying atypical lymphoid cells was observed in pleural and pericardial fluids, and on further investigation, the patient was discovered to have acute T-cell lymphoblastic lymphoma/leukemia. In this case, it was this finding of lymphophagocytosis associated with atypical lymphoid cells that prompted us to search actively for the underlying cause, which turned out to be a hematological malignancy.

A 17-year-old boy presented with chest pain, dyspnea, and fever for 4 days. Clinically, cardiac tamponade was suspected. Echocardiography suggested moderate pericardial effusion with constrictive pericarditis. Further investigations documented pleural effusion. Hemogram was normal, with a differential leukocyte count of neutrophils (90\%), lymphocytes (7\%), and monocytes (3\%). Serum biochemistry revealed an elevated lactate dehydrogenase level of 1,025 U/L (normal range: $125-225 \mathrm{U} / \mathrm{L}$ ). Viral markers for HIV, hepatitis B, and hepatitis $C$ were nonreactive. Cytology of the pericardial and pleural revealed prominent lymphophagocytosis and atypical lymphoid cells displaying focal nuclear contour irregularities, coarse chromatin, prominent nucleoli, and scanty cytoplasm ( Fig. 1A-C). PET-CT (positron emission tomography-computed tomography) showed a large mass in anterior and middle mediastinum encasing the aorta, superior vena cava, and left carotid artery, causing a tracheal shift to the right side, with mass effect extending to the left supraclavicular and cervical region ( $\boldsymbol{-}$ Fig. 2 ). The left cervical lymph nodes

\author{
Davinder Paul ${ }^{2} \quad$ Naved Aslam³
}

Address for correspondence Ruchita Tyagi, MD, Department of Pathology, Dayanand Medical College and Hospital, Tagore Nagar, Civil Lines, Ludhiana 141001, Punjab, India (e-mail: ruchitatyagi@gmail.com).

and para-aortic lymph nodes were also enlarged. Excisional biopsy of the left cervical lymph node showed effaced nodal architecture with diffuse infiltration by round monomorphic cells having fine chromatin, conspicuous nucleoli, and scant cytoplasm ( - Fig. 1D). These cells were positive for CD3, CD10, LCA (leukocyte common antigen), and TdT (terminal

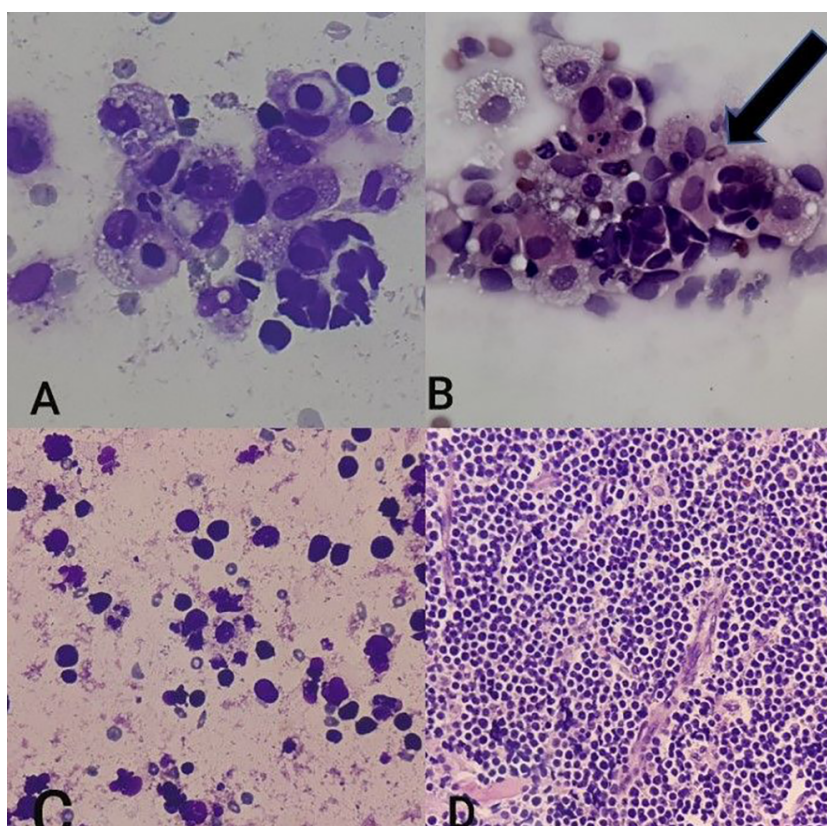

Fig. 1 (A) May-Grunwald-Giemsa staining and (B) hematoxylin and eosin (H\&E) staining showing lymphophagocytosis in pericardial fluid (400×). (C) Atypical lymphoid cells in pleural fluid (H\&E, 400×). (D) Histopathology of lymph node showing infiltration by sheets of atypical lymphoid cells (H\&E, 100×). published online May 19, 2021
DOI https://doi.org/ $10.1055 / \mathrm{s}-0041-1727582$ ISSN $0974-2727$
(C2021. The Indian Association of Laboratory Physicians.

This is an open access article published by Thieme under the terms of the Creative Commons Attribution-NonDerivative-NonCommercial-License, permitting copying and reproduction so long as the original work is given appropriate credit. Contents may not be used for commercial purposes, or adapted, remixed, transformed or built upon. (https://creativecommons.org/licenses/by-nc-nd/4.0/).

Thieme Medical and Scientific Publishers Pvt. Ltd. A-12, 2nd Floor, Sector 2, Noida-201301 UP, India 


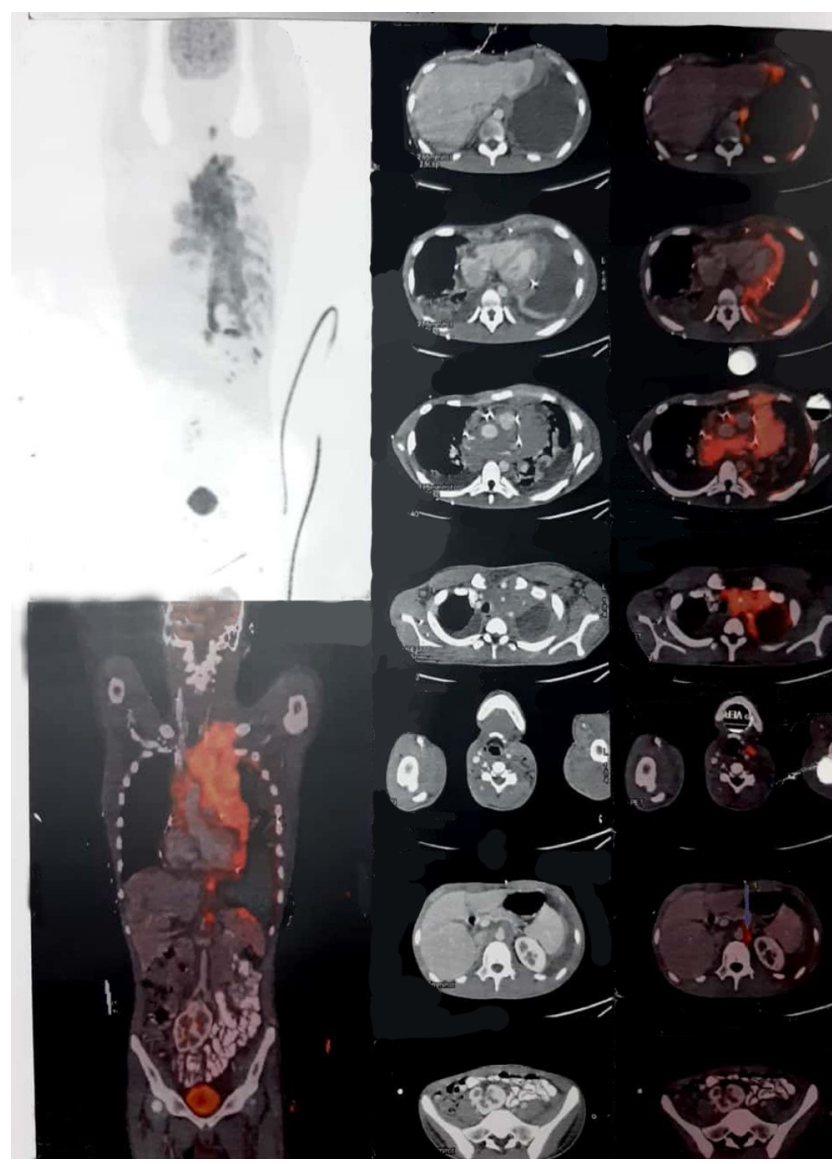

Fig. 2 PET-CT (positron emission tomography-computed tomography) showing FDG avid large mass in the anterior and middle mediastinum encasing the aorta, superior vena cava, and left carotid artery, causing a tracheal shift to the right side, with mass effect extending to the left supraclavicular and cervical region.

deoxynucleotidyl transferase) on immunohistochemistry (IHC), with an MiB-1 index of $98 \%$ in the highest proliferating areas. CD20 and CD34 were negative on IHC. Hence, the diagnosis of T-cell acute lymphoblastic leukemia/lymphoma was made. Bone marrow aspiration and biopsy showed normocellular marrow with normal hematopoietic elements, without any hemophagocytosis or lymphomatous infiltration. The patient was administered cyclophosphamide $400 \mathrm{mg}$ OD and dexamethasone $800 \mathrm{mg}$ BD intravenously for 3 days. He tolerated the prephase chemotherapy well with good response and is being treated with Berlin-FrankfurtMünster-90 protocol. Till date, he is showing clinical benefit to chemotherapy. His pericardial effusion has resolved and pleural fluid is negative for malignant cells.
HLH can be a secondary response to malignancies such as non-Hodgkin lymphoma. ${ }^{2-4}$ The diagnosis of primary HLH is made by the presence of fever, splenomegaly, cytopenias, ferritin levels > $500 \mathrm{~g} / \mathrm{L}$, hypertriglyceridemia, hypofibrinogenemia, microscopic evidence of hemophagocytosis in the bone marrow, spleen, or lymph nodes, and CD25 count $<2,400 \mathrm{U} / \mathrm{mL}^{1,2}$ Our patient had fever and lymphophagocytosis. The absence of other criteria for primary HLH led to further work-up for the underlying cause of lymphophagocytosis. Atypical lymphoid cells in both pleural and pericardial fluids provided a vital clue, as pericardial effusion demonstrating atypical cells and prominent lymphophagocytosis has been reported in NK (natural killer)/T-cell lymphoma. ${ }^{3}$ Primary effusion lymphoma can also show atypical lymphoid cells with lymphocytic hemophagocytosis. ${ }^{4}$

In our patient, lymphophagocytosis in pleural and pericardial fluids caught our attention, and the accompanying atypical lymphoid cells led to the diagnosis of acute T-cell lymphoblastic lymphoma/leukemia, which resulted in the prompt administration of chemotherapy. Thus, hemophagocytosis in the fluids should be considered an ominous finding and alert the clinician to the remote possibility of underlying lymphoma, which can take a fulminant course if not managed timely.

\section{Funding \\ None.}

\section{Conflict of Interest}

None declared.

\section{Acknowledgment}

None.

\section{References}

1 Taheri ZM, Ryahi MM, Nadji SA, Mohammadi F. Transient localized hemophagocytosis in pleural effusion. Tanaffos 2010; 9:61-63

2 Abdelfatah M, Dumford D, Murphy C. Hemophagocytic lymphohistiocytosis (HLH) with B cell lymphoma: a rare lethal cause for fever of unknown origin. Chest 2014;146:195A

3 Han Y, Kim KH, Choi IH. Cytological findings of NK/T-cell lymphoma in pericardial effusion: a case report with a review of the literature. Indian J Pathol Microbiol 2019;62(3):473-476

4 Xian JZ, Cherian SV, Golardi N, Estrada-Y-Martin RM. A 32-year-old man with HIV infection, pleural effusions, and lymphadenopathy. Chest 2018;154(5):e147-e151 